\title{
$\operatorname{arCOS} D E S I G N$
}

\section{Jornalismo online e design de interfaces: avaliação comparativa da usabilidade dos sites G1, Folha de São Paulo e Estadão}

Alberto Santágueda (PUC-Rio, Brasil)

albertosantagueda@gmail.com

Rua Marquês de São Vicente, 225, Gávea

Rio de Janeiro, RJ. CEP: 22451-900

Lisle Menezes (PUC-Rio, Brasil)

lislemeneses@gmail.com

Luiz Agner (PUC-Rio, Brasil)

luizagner@gmail.com 


\title{
Jornalismo online e design de interfaces: avaliação comparativa da usabilidade dos sites G1, Folha de São Paulo e Estadão
}

Resumo: Este trabalho vai apresentar uma avaliação comparativa da usabilidade dos sites jornalísticos G1, Folha de S. Paulo e Estadão, alguns dos principais veículos de notícias Brasil. O objetivo é diagnosticar inconsistências do design a partir da observação sistemática da interação dos leitores. O estudo emprega testes de usabilidade de comparação para verificar como ocorre a busca de dados simples nos veículos selecionados. O trabalho contempla a definição de algumas recomendações de design para correção de problemas encontrados nos sites avaliados.

Palavras-chave: jornalismo online, ux design, teste de usabilidade comparativo

\section{Online journalism and interface design: a comparative usability evaluation of G1, Folha de São Paulo and Estadão}

\begin{abstract}
This paper provides a comparative assessment of the usability of sites G1, Folha de S. Paulo and Estadão, some of the major news portals in the Brazilian scenario. The aim is to diagnose design inconsistencies from the systematic observation of the interaction of readers. The study employs usability testing for comparison to see how the search for simple data on selected vehicles occurs. The work includes the definition of design recommendations for correcting problems found in the three sites evaluated.
\end{abstract}

Key words: online journalism, ux design, comparative usability testing 


\section{Introdução}

Este trabalho se propôs a realizar uma avaliação comparativa da usabilidade dos websites jornalísticos G1, Folha de S. Paulo e Estadão. Estes veículos foram escolhidos por sua influência, qualidade, credibilidade de conteúdo e grande acesso de leitores internautas. A avaliação comparativa através de testes de usabilidade foi aplicada por ser uma forma assertiva de diagnosticar pontos fortes e fracos de cada meio jornalístico, apontando soluções para a usabilidade e arquitetura de informação desses ambientes na web.

O objetivo deste trabalho foi diagnosticar inconsistências existentes nos sites de webjornalismo, a partir da observação sistemática da interação dos leitores durante a busca de dados simples, como o valor do dólar no dia e a previsão do tempo.

\section{Aspectos atuais do jornalismo online}

Segundo Canavilhas (2003, p. 68), "o grande desafio feito ao webjornalismo é a procura de uma 'linguagem amiga' que imponha a webnotícia, uma notícia mais adaptada às exigências de um público que exige maior rigor e objetividade". Para isso, entendemos ser necessário compreender como se dá a busca de informações em cada jornal online, de modo a adaptar a notícia às diferentes necessidades de interação do público da web.

O processo de adaptação da notícia ao público existe no meio impresso, na TV e no rádio, assim como a web, cada um com suas características específicas. É importante ressaltar que nenhuma nova mídia transpõe as anteriores, mas apenas provoca adaptações, sem nunca substituí-las, e todas, na verdade, se complementam, como afirma Palácios (2003, p. 80-81):

"Entendido o movimento de constituição de novos formatos midiáticos não como um processo evolucionário linear de superação de suportes anteriores por suportes novos, mas como uma articulação complexa e dinâmica de diversos formatos jornalísticos, em diversos suportes, "em convivência” e complementação no espaço midiático, as características do Jornalismo na web aparecem majoritariamente como Continuidades e Potencializações e não, necessariamente, como Rupturas com relação ao jornalismo praticado em suportes anteriores. Com efeito, é possível argumentar-se que as características elencadas anteriormente como constituintes do Jornalismo na web 
podem, de uma forma ou de outra, ser encontradas em suportes jornalísticos anteriores, como o impresso, o rádio, a TV, o CD-Rom" (PALÁCIOS, 2003, p. 80-81).

A apresentação do conteúdo jornalístico na web se beneficia de uma gama de recursos que se tornam cada vez mais acessíveis, devido ao avanço tecnológico. No entanto, o avanço acontece de maneira gradual, onde o usuário é levado a se adaptar a mudanças em pequenas doses, ao mesmo tempo que se acomoda e aprova ou reprova cada modificação.

Mais uma vez, tal como observado no surgimento de novas mídias, que não romperam drasticamente com as antigas, cada nova ferramenta de disposição de conteúdo jornalístico na web também não rompe com o passado. Apenas contribui para a evolução de sua linguagem.

"É claro que a maioria dos sites na web se limitam a uma transposição de conteúdos, sem tirarem ainda total partido do potencial que a interatividade representa, mas verifica-se em todos um movimento no sentido de aumentar a interatividade nos seus sites, e isso está a reconfigurar a atividade e práticas dos jornalistas, a par com novas formas de apresentarem os seus produtos" (GRADIM, 2003, p. 118).

Para Agner (2013), os novos dispositivos tecnológicos e a internet habilitaram novos modos de leitura que têm colocado em xeque as empresas de comunicação em todo o mundo. "A circulação mundial de jornais impressos tem diminuído, segundo a Associação Mundial de Jornais e Editores de Notícias. Exemplos recentes desta crise podem ser citados como o fim da edição em papel da tradicional revista norte-americana Newsweek após 80 anos, além da morte do Jornal da Tarde, de São Paulo, após 46 anos de uma marcante trajetória”. Diante dessas mudanças, a indústria da mídia se reconfigura e o jornalismo procura se reinventar.

De todas as mídias em que o jornalismo atua, a online é a que mais sofre adaptações em sua estrutura devido à sua própria natureza. Esse diferencial tem como objetivo aproximar o jornal online do leitor usuário, na tentativa de fazê-lo acompanhar as páginas de notícias diariamente, como acontecia com o jornal impresso. Para que essa aproximação aconteça, é importante que se conheça o usuário e entenda as suas necessidades, o que pode ser realizado a partir de técnicas de pesquisa, entre elas, os testes de usabilidade. 


\section{Aplicação de testes de usabilidade de comparação}

Esta pesquisa observou a eficácia da procura de informações específicas pelo leitor no webjornalismo, particularmente na busca de dados simples, como previsão do tempo e cotação do dólar. Observou-se que os veículos noticiosos online não costumam seguir o mesmo padrão de design de interfaces na apresentação dessas informações, o que acaba por confundir os leitores, que não podem empregar o conhecimento de navegação já adquirido.

Acreditamos que para encontrar uma "linguagem amiga" (CANAVILHAS, 2003), e aprimorar a comunicação do sistema com o leitor, é necessário que se reestude o ambiente dos webjornalismo, propondo soluções mais integradas de interação, cuja necessidade pode ser evidenciada a partir de testes de usabilidade.

Segundo RUBin e CHISNELL (2008, p. 21):

"Teste de usabilidade é um processo que emprega pessoas representantes do público-alvo como participantes de testes para avaliar o grau em que um produto atende a critérios de usabilidade específicos. A inclusão de participantes representativos diferencia os testes de usabilidade das técnicas de perícia, pois estas não necessitam de utilizadores representativos como parte do processo" (tradução livre).

Segundo os autores, pode haver diferentes modelos de teste de usabilidade, com diferentes intervenções do moderador e diversas formas de avaliação das interfaces pesquisadas. Os sistemas avaliados podem ser qualquer sistema eletrônico ou web, como as páginas de webjornalismo por exemplo.

"O teste de usabilidade é uma ferramenta de pesquisa que tem raízes na metodologia experimental clássica. A gama de testes diferenciados que se pode realizar é considerável. Desde verdadeiros experimentos clássicos com tamanhos consideráveis de amostra, até testes complexos de design para estudos qualitativos informais, com apenas um participante. Cada abordagem do teste tem diferentes objetivos, tempo e necessidades de recursos" (RUBin e CHISNELl, 2008, p. 21, tradução livre).

O teste pode servir a diferentes propósitos que envolvem diferentes tipos de tarefas, medidas de performance e disposição de escalas, entrevistas ou inspeções a serem aplicadas. Assim, podem existir testes de exploração, testes de avaliação, ou testes de validação, conforme aplicados, respectivamente, em 
etapas iniciais, intermediárias ou finais do ciclo de desenvolvimento de produtos. É possível avaliar um único ambiente por vez ou diversos ambientes simultâneos - o que é chamado de teste de usabilidade de comparação. Neste caso, a mesma tarefa é executada em diferentes sistemas:

"O teste de comparação não é associado a nenhum ponto específico do ciclo de desenvolvimento de um produto. Nos primeiros estágios, pode ser usado para comparar diferenças entre estilos de interfaces através do teste de exploração; nos ciclos intermediários, pode ser usado para medir a efetividade de um elemento integrante da interface; no final do ciclo, um teste de comparação pode ser usado para ver como a liberação de um produto atinge um produto concorrente. O teste de comparação pode ser usado como uma junção dos demais testes sendo que seu objetivo é realização de comparações em todos os níveis" (FERREIRA, 2002, p. 12).

Em nosso estudo, realizamos uma seqüência de testes de usabilidade de comparação com o objetivo de observar a facilidade de busca de dados simples nos três veículos selecionados. Os testes de usabilidade contribuem para que o design de interfaces possa alcançar resultados eficazes, com interfaces de uso mais fácil, aprimorando os projetos, reduzindo ou evitando possíveis erros que possam gerar custos.

"Do ponto de vista de algumas empresas, os testes de usabilidade são parte de um esforço maior para melhorar a rentabilidade dos produtos. Há muitas razões para fazê-lo, o que no final também beneficia os usuários: as decisões de design são baseadas em dados coletados a partir de usuários representativos para expor os problemas de design de modo a que possam ser corrigidos, minimizando ou eliminando a sua frustração" (RUBin, CHISNELL, 2008, p. 21, tradução livre).

Para o webjornalismo, avaliar e adaptar as interfaces às necessidades dos seus leitores configuram um processo onde se podem encaixar os testes de usabilidade. Este estudo se dá em um contexto em que se deve compreender que os modelos de webjornalismo existentes não alcançaram a maturidade desejada. De acordo com PALÁcıos (2003, p. 76) ainda não foram estabelecidos formatos-padrão para o jornalismo online: "é importante que se ressalte que não acreditamos existir um formato canônico, nem tampouco 'mais avançado' ou 'mais 
apropriado' no jornalismo que hoje se pratica na web". Ou seja, muitos estudos ainda podem ser realizados para tornar o uso das interfaces do webjornalismo mais fluido, o que representa uma necessidade hoje indispensável.

\section{0 roteiro desta pesquisa}

Como foi colocado, a metodologia desta pesquisa incluiu a aplicação de uma seqüência de testes de usabilidade de comparação. O processo se deu em três etapas: além da observação sistemática da interação dos leitores com as interfaces selecionadas, foram aplicados questionários nos momentos de pré e pós-teste. $\mathrm{O}$ primeiro questionário mapeou informações demográficas dos participantes e o segundo coletou impressões a respeito da navegação em cada sistema.

Nossa pesquisa identificou como seu problema de trabalho a ausência de padrões para as seções de serviços no webjornalismo. Para guiar o estudo, foram consideradas as seguintes hipóteses de trabalho: (a) não existe convenção no posicionamento dos componentes de cotação de moedas estrangeiras e de previsão do tempo nos jornais online; (b) a excessiva aglutinação de informações nas páginas iniciais torna confusa a busca por informações; e (c) a escolha de tipografias serifadas, remetendo ao universo do jornal impresso, pode se tornar inadequada para leitura em telas digitais. O objetivo deste trabalho buscou mensurar a usabilidade destes componentes e identificar se é eficaz a tradução de padrões de diagramação utilizados nos jornais impressos para a mídia digital nos sites apresentados.

Para analisar os três sites escolhidos foi selecionada uma amostra intencional com seis usuários na faixa de idade de 25 a 40 anos, com familiaridade na leitura de jornais impressos e online há pelo menos cinco anos. Todos com curso superior e que acessam diariamente jornais online no trabalho ou em casa. Os participantes dos testes utilizam a internet para ler notícias, mandar e-mails, interagir em redes sociais e realizar compras em comércio eletrônico.

Os três veículos foram escolhidos por serem sites muito conhecidos e presentes na mídia impressa, com amplo acesso do publico leitor. Partindo do princípio de que a sequência de apresentação dos websites aos participantes poderia influenciar o resultado, fez-se uma análise combinatória para determinar que cada participante os avaliasse numa sequência diferente. A pesquisa se baseou na área de serviços dos websites, por isso foram escolhidas as seções de indicadores econômicos e de previsão do tempo para os testes de usabilidade. Os cenários de uso para aplicação dos testes de usabilidade são apontados nas tabelas 1 e 2 . 
Tabela 1. Roteiro para aplicação do cenário de uso 1.

\begin{tabular}{|c|c|}
\hline Tarefa & $\begin{array}{l}\text { Encontrar a cotação do dólar nos seguintes sites: Estadão, Folha de São } \\
\text { Paulo e G1. }\end{array}$ \\
\hline Estado de início & Home page dos três sites de notícias. \\
\hline Objetivo & $\begin{array}{l}\text { Observar e analisar a eficácia da navegação e da leitura dentro de cada } \\
\text { site acima com foco na busca de dados simples. }\end{array}$ \\
\hline Previsão & 2 minutos \\
\hline Cenário & $\begin{array}{l}\text { Você pretende tirar férias e viajar para os Estados Unidos. Navegando } \\
\text { num site de notícias, você descobre que houve aumento nos impostos } \\
\text { para o uso de cartões de débito e pré-pagos no exterior, então você } \\
\text { decide comprar e levar dólares em espécie. }\end{array}$ \\
\hline
\end{tabular}

Fonte: Elaborado pelos autores, com base na pesquisa realizada.

Tabela 2. Roteiro para aplicação do cenário de uso 2.

\begin{tabular}{|l|l|}
\hline Tarefa & $\begin{array}{l}\text { Procurar a previsão do tempo do Rio de Janeiro nos seguintes sites: } \\
\text { Estadão, Folha de São Paulo e G1. }\end{array}$ \\
\hline Estado de início & Home page dos três sites de notícias. \\
\hline Objetivo & $\begin{array}{l}\text { Observar e analisar a eficácia da navegação e da leitura dentro de cada } \\
\text { site acima com foco na busca de dados simples. }\end{array}$ \\
\hline Previsão & $\begin{array}{l}\text { minutos } \\
\text { Cenário }\end{array}$ \\
\hline Janeiro em sites de notícia.
\end{tabular}

Fonte: Elaborado pelos autores, com base na pesquisa realizada.

Os testes de usabilidade de comparação foram realizados em notebooks com câmeras embutidas e programas de gravação simultânea de vídeo e áudio da tela e do usuário, como o Camtasia (para Windows e Mac). Foram feitas anotações em blocos de nota durante a realização das tarefas e o Google Drive foi utilizado como ferramenta de criação dos questionários online, respondidos pelos participantes em notebooks e cujas respostas foram computadas automaticamente.

Observamos métricas e parâmetros quantitativos e qualitativos como por exemplo: a quantidade de usuários que conseguiram concluir a tarefa; o tempo levado para a sua realização de cada uma e o elenco de problemas de navegação desvelados pelos usuários durante a busca de informações em cada sistema de webjornalismo. 


\section{Apresentação parcial dos dados da pesquisa}

Idade

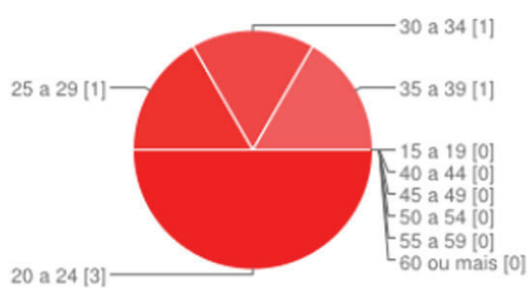

$\begin{array}{llllll}15 \text { a } 19 & 0 & 0 \% & 40 \text { a } 44 & 0 & 0 \% \\ 20 \text { a } 24 & 3 & 50 \% & 45 \text { a } 49 & 0 & 0 \% \\ 25 \text { a } 29 & 1 & 17 \% & 50 \text { a } 54 & 0 & 0 \% \\ 30 \text { a } 34 & 1 & 17 \% & 55 \text { a } 59 & 0 & 0 \% \\ 35 \text { a } 39 & 1 & 17 \% & 60 \text { ou mais } & 0 & 0 \%\end{array}$

\section{Grau de escolaridade}

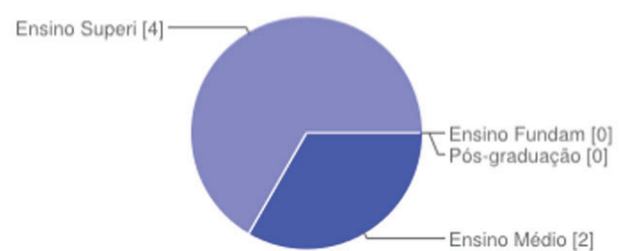

Ensino Fundamental $\quad 0 \quad 0 \%$

Ensino Médio $2 \quad 33 \%$

Ensino Superior $\quad 4 \quad 67 \%$

Pós-graduaçăo $\quad 0 \quad 0 \%$

\section{Quantas horas por dia você navega na Web?}

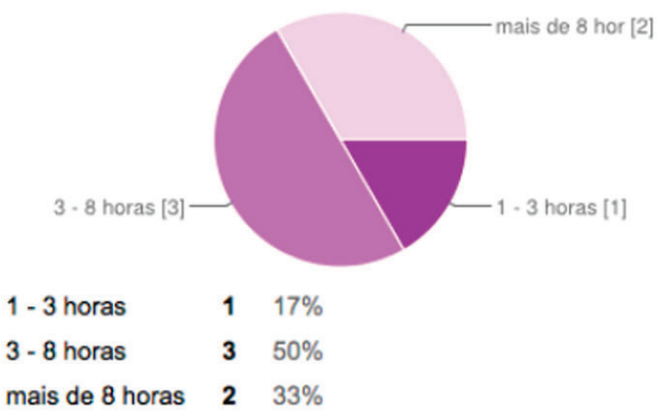

\section{Costuma ler jornais em papel?}

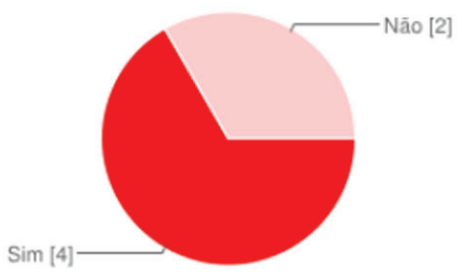

Sim $467 \%$

Não $233 \%$

Você acessa sites de notícias?

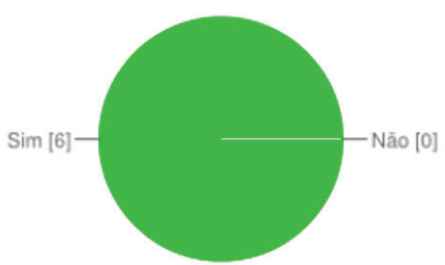

$\operatorname{Sim} 6100 \%$

Não $\quad 0 \quad 0 \%$

Você conhece algum dos seguintes sites:

Estadão, Folha de São Paulo e G1.com.br?

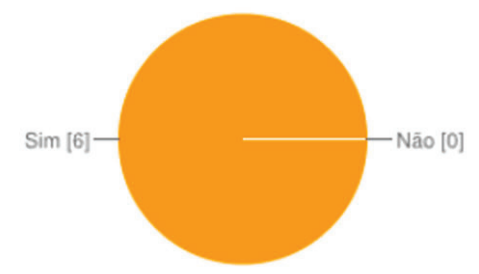

Sim 6 100\%

Não $\quad 0 \quad 0 \%$

Figura 1. Dados demográficos dos usuários coletados no questionário de pré-teste.

A maioria dos usuários participantes realizou as tarefas propostas para o teste em mais tempo do que o previsto. A tarefa 1, para todos os sites de notícias, foi realizada em média em seis minutos. Já a tarefa 2, prevista em três minutos, foi feita em média em cinco minutos. 
Observou-se que, em alguns casos, até 90\% do tempo total correspondeu apenas à busca pela localização das seções, sendo que somente os 10\% restantes corresponderam à encontrar o dado em si, o que demonstra dificuldade dos leitores com a arquitetura de informação nos sites de webjornalismo.

Na tarefa 1, o G1 obteve o melhor desempenho médio, 25 segundos abaixo do esperado. O Estadão manteve o tempo médio previsto e a Folha de S. Paulo ultrapassou em 45 segundos o tempo esperado. Nota-se ainda que, em todos, os leitores navegaram duas a quatro vezes mais páginas do que o necessário, e deram de três a cinco vezes mais cliques, em média. Percebemos ainda que na Folha e no G1 a informação da cotação do dólar estava na página inicial (home), sendo necessário apenas o uso do scroll para achar a informação.

Para a Tarefa 2, a Folha de S. Paulo obteve melhor desempenho em eficiência, com menos da metade do tempo previsto, sendo ultrapassada 30 segundos pelo site G1. O jornal online Estadão manteve o tempo previsto. Verificouse que o site Estadão (que tem o dado acessível no topo da página inicial) teve média de navegação de cinco páginas a mais que o necessário, o G1 foi o mais próximo, e Estadão, o mais distante (tabela 3).

Tabela 3. Desempenho dos jornais online por tarefa.

\begin{tabular}{|l|c|c|c|c|}
\hline Tarefa 1 & Tempo estimado & Tempo gasto & Páginas navegadas & Cliques \\
\hline Estadão & 2'00” & 2'05” & 3,7 & 4 \\
\hline Folha de S. Paulo & 2'00” & 2'45” & 4,2 & 5,5 \\
\hline G1.com & 2'00” & 1'35” & 3,2 & 3 \\
\hline Tarefa 2 & Tempo estimado & Tempo gasto & Páginas navegadas & Cliques \\
\hline Estadão & 3'00” & 2'55” & 5 & 8,3 \\
\hline Folha de S. Paulo & 3'00” & 1'15” & 3 & 9,2 \\
\hline G1.com & 3'00” & 1'45” & 3,8 & 5,7 \\
\hline
\end{tabular}

Fonte: Elaborado pelos autores com base na pesquisa.

\section{Análise e recomendações de Design}

Formulamos recomendações de design para solucionar problemas observados nos três sites de webjornalismo analisados, durante os testes de usabilidade de comparação. Cada ponto foi classificado em níveis de curto, médio e longo prazo, indicando o que precisa ser modificado de modo mais urgente para facilitar a navegação dos leitores. 
As recomendações de curto prazo relacionam-se aos problemas mais graves que podem limitar bastante a navegação do leitor, as de médio prazo são problemas que devem ser corrigidos a fim de não prejudicar a conclusão eficaz das tarefas de busca de dados simples, e as de longo prazo diminuem a satisfação dos usuários.

\subsection{Recomendações de curto prazo}

- Baixa eficiência dos resultados da busca por palavras-chave: A busca por palavras-chave nos sites de webjornalismo leva ao conteúdo das notícias, mas não às páginas de seções, como era esperado pelos usuários participantes, contrastando com suas expectativas e modelo mental.

- Poucas opções de localização e ausência de geolocalização: Nos testes realizados fora do Rio de Janeiro, todos os usuários comentaram sobre a falta da sua cidade na listagem principal, relatando frustração com este fato. Além disso, os usuários demoraram a achar a sua localização. Os sites falham em mostrar a cidade do usuário na previsão do tempo, não fazendo uso de cookies ou scripts de localização (figura 2).

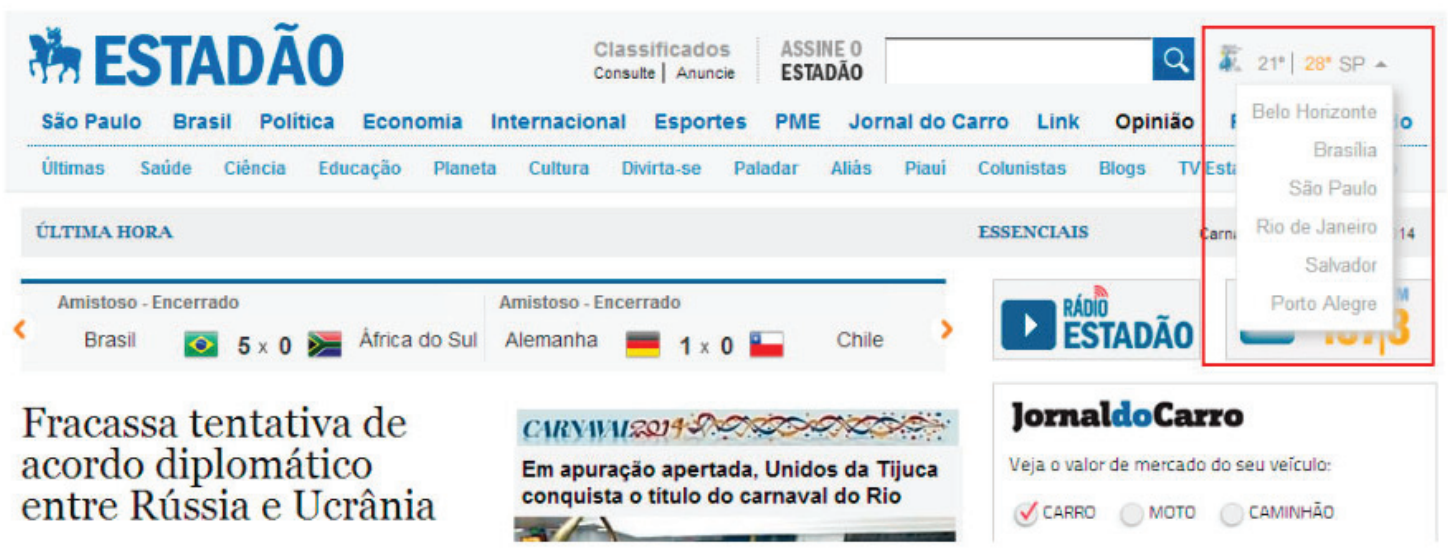

Figura 2. Na home page do Estadão há poucas opções de localização do usuário, o que gera frustração.

\subsection{Recomendações de médio prazo}

- Banners intrusivos dificultam a conclusão de tarefas: Deve-se evitar utilizar elementos publicitários intrusivos que cubram as informações propositalmente, especialmente em dispositivos sem suporte ao Flash, pois pode ocorrer do botão de "Fechar" não aparecer na tela (figura 3). 


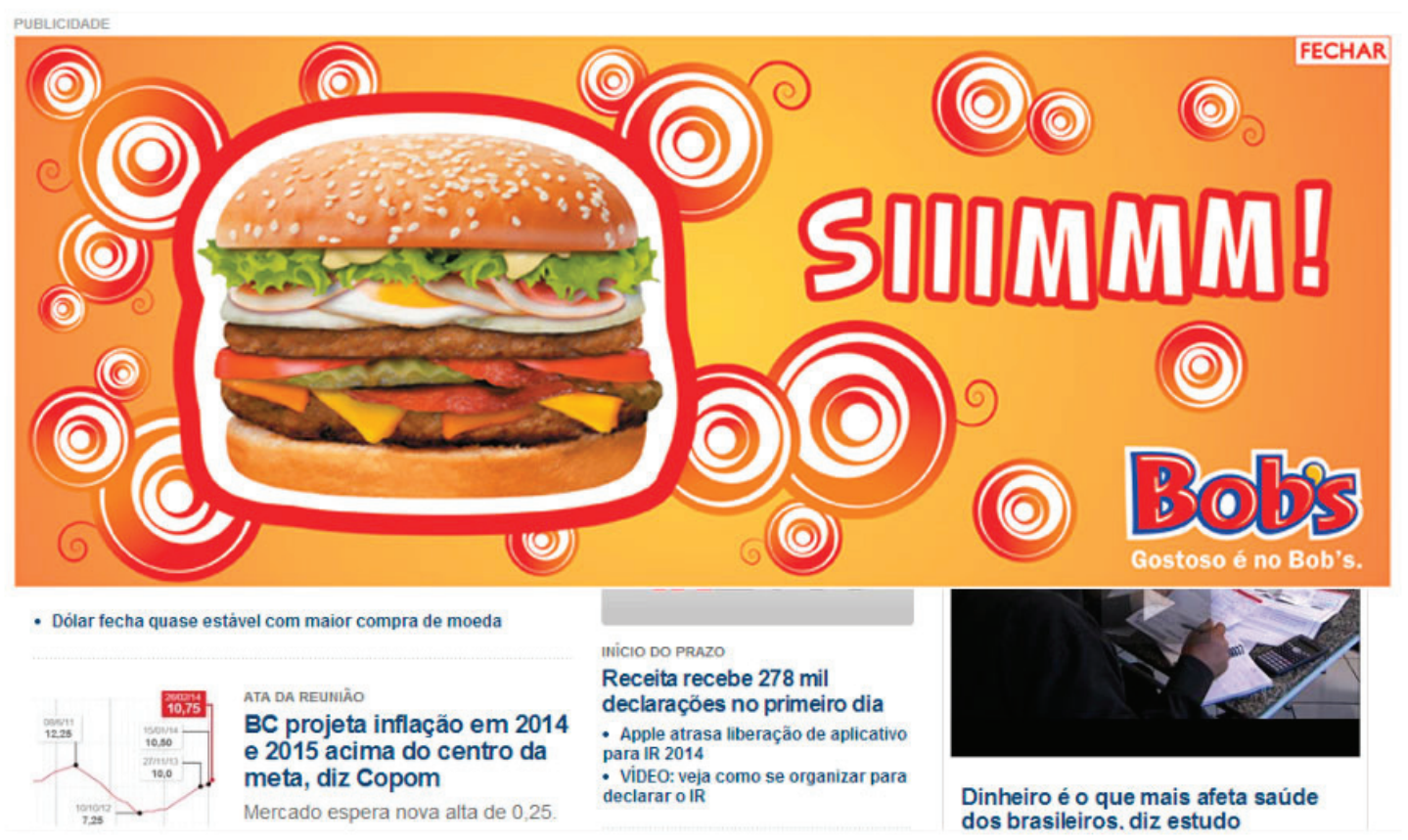

Figura 3. Exemplo de banner intrusivo no site G1 (maio de 2014).

- Diagramação: blocos de texto excessivamente aglutinados: Algumas práticas de diagramação do jornal impresso (que pode ser dobrado e aproximado para que se foque em parte do conteúdo) podem não funcionar bem na diagramação para a tela. Deve-se avaliar a quantidade de informação e manter a respiração nas colunas de texto e fim de permitir a boa leitura das telas nos sites do webjornalismo e evitar a poluição visual (figura 4 ). 


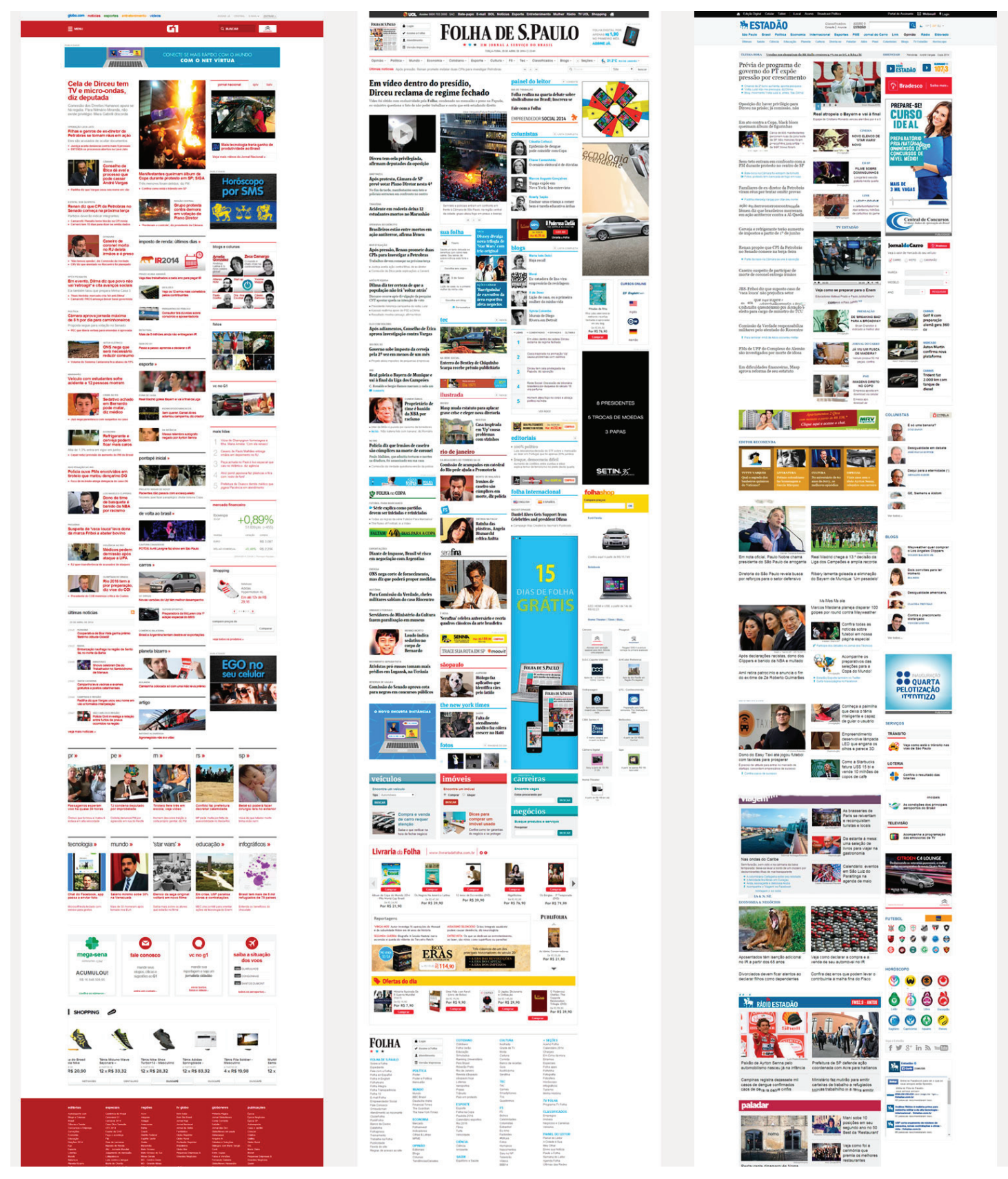

Figura 4. O excesso de informação na home page e a verticalização excessiva do layout das páginas do G1, Folha e Estadão podem desestimular o leitor. 


\subsection{Recomendações de longo prazo}

- Excesso de verticalização desestimula a navegação: A maioria dos leitores prefere explorar a home antes de procurar outros recursos. Como os sites de notícia são demasiadamente verticalizados, os leitores precisam rolar bastante a página inicial e podem desistir de continuar navegando. Por vezes, a informação buscada estava presente na home page mas nenhum usuário completou sua tarefa na página inicial.

Uma solução possível para amenizar os efeitos da verticalização excessiva seria o desenvolvimento de um link de "voltar ao topo" no momento em que o menu principal não estiver visível com o uso da rolagem da tela. Outra forma de resolver essa questão seria criar o menu principal fixo no topo da tela (figura 4).

\section{Algumas conclusões provisórias}

Podemos concordar com Canavilhas (2003), quando o autor propõe que o grande desafio do webjornalismo tem sido a busca de uma linguagem amiga, onde a informação seja adaptada às exigências de um público que exige cada vez mais. Pudemos endossar também as críticas de Gradim (2013), autora atenta às transformações da mídia, para a qual a maioria dos websites de jornais ainda se limita ao arremedo de conteúdos impressos, sem aproveitar completamente o potencial de interatividade das novas mídias.

De acordo com a verificação feita durante os nossos testes de usabilidade comparativos, concluímos que a melhor forma de apresentar os serviços em sites de notícias seria através de uma combinação dos melhores pontos dos três objetos de estudo. Alguns usuários pontuaram que a diagramação e a escolha da tipografia do webjornalismo lembravam muito o jornal impresso: esta analogia não foi, entretanto, considerada um fator positivo, pois a tela do computador distorce muito as fontes serifadas empregadas nos títulos. Além disso, como apontado por nossas observações, as páginas iniciais não foram percorridas em sua totalidade por todos os leitores devido provavelmente à excessiva quantidade de informação e acentuada verticalização -- um problema presente em grande parte dos sites de webjornalismo.

Este estudo formulou e apresentou algumas recomendações para as áreas de serviços em sites de notícias, com destaque para a necessidade de buscas capazes de filtrar o conteúdo textual das notícias ao mesmo tempo que outros conteúdos e dados relevantes para o usuário. É importante ainda mostrar um 
adequado contraste entre plano de fundo e cor do texto, e hierarquizar de modo eficiente o conteúdo no site.

Como lições aprendidas da aplicação do nosso método de pesquisa, sublinhamos que o uso do protocolo think-aloud (pensamento em voz alta) pelos usuários durante os testes foi particularmente importante, pois atribuiu valor às informações, contextualizando as descobertas, o que é essencial na análise dos achados. Além disso, empregar o programa Camtasia forneceu informações indispensáveis pois com ele foi possível capturar, junto às telas, as expressões de frustração ou de contentamento dos usuários.

Como desdobramentos futuros desta pesquisa com testes de usabilidade comparativos, aplicados ao webjornalismo brasileiro, verificamos que o uso de um equipamento de eye-tracking (rastreamento do olhar) poderá nos trazer novos e importantes insights, a fim de radiografar o fluxo de visão dos leitores nos sistemas de comunicação estudados.

Um outro ponto importante a ser destacado é a atual convergência para a mobilidade digital, onde as interfaces para desktop e mobile (smartphones e tablets) terão maior comunhão de seus designs. Após o término da produção deste trabalho, algumas modificações nos sites estudados ocorreram. O site G1 adotou, em sua interface para desktop, um ícone de menu comum às interações touch-screen (por toques), facilitando a compreensão das funções nos celulares e tablets. O portal Estadão reformulou toda a sua interface, tornando-se menos poluído visualmente, e mais rico em exposição de imagens e vídeos. A largura de seu site agora é mais estreita, facilitando a leitura em dispositivos móveis. As notícias estão contidas em boxes maiores, o que as tornou mais atrativas, e a navegação é menos cansativa e mais agradável.

As recentes alterações dos sites G1 e Estadão (figura 5) sanaram alguns problemas previamente descobertos por este trabalho. A página inicial do Estadão não conta mais com o aparecimento de banners intrusivos inesperados. Sua diagramação melhorou consideravelmente, com boxes de notícias com melhor respiro e maior possibilidade de leitura. O conteúdo total da tela ocupa menos espaço, dando uma sensação de verticalização bem menor.

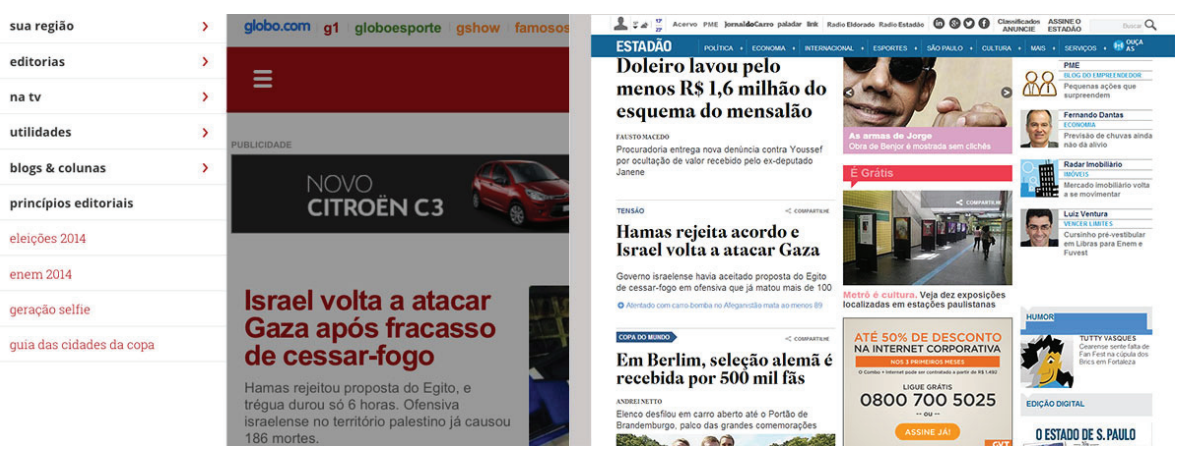

Figura 5. Alterações nos sites G1 e Estadão: maior convergência com dispositivos móveis. 
As hipóteses apontadas por este trabalho foram validadas. De fato, após a avaliação dos resultados, percebemos que não existe uma convenção na posição dos componentes de cotação de moedas estrangeiras e de previsão do tempo nos jornais online pesquisados. A excessiva aglutinação de informações nas páginas iniciais realmente tornou confusa a busca por informações, com ressalva ao Estadão que, após a reformulação em sua interface, melhorou muito nesse quesito, tornando-se muito mais agradável de navegar. Por último, a escolha de tipografias serifadas, remetendo ao universo do jornal impresso, de fato se tornou inadequada para leitura em telas digitais. Novamente, cabe aqui referir o Estadão, que não abandonou a fonte serifada, mas a tem utilizado de maneira inteligente, em maior tamanho e em boxes maiores, com maior respiração, conseguindo manter a tradição e a relação com o impresso, sem deixar de se posicionar adequadamente no ambiente web - de forma limpa e clara, com um tom equilibrado entre o moderno e o tradicional.

É importante sublinhar que, assim como Palácios, não acreditamos existir um formato canônico para o webjornalismo. Muitos estudos ainda devem ser realizados para tornar as interfaces do webjornalismo mais intuitivas, uma necessidade hoje indispensável.

\section{Referências}

AGNER, Luiz. Jornalismo Digital nos Tablets e a Interação Gestual. In: BARBOSA, A; RANGEL, M.; RAPOSO, M. (orgs.) Ergonomia Design Usabilidade Interação. Juiz de Fora: MAMM/Museu de Arte Murilo Mendes. UFJF/Universidade Federal de Juiz de Fora, 2013. 184p.

CANAVILHAS, João. Webjornalismo: Considerações Gerais sobre Jornalismo na Web. In: FIDALGO, Antonio; SERRA, Paulo. (org). Jornalismo Online: Informação e Comunicação Online. Volume I. Universidade da Beira Interior. Covilhã , Portugal , 2003.

FERREIRA, Kátia Gomes. Teste de Usabilidade. Monografia de Final de Curso em Especialização em Informática. Departamento de Ciência da Computação. Universidade Federal de Minas Gerais - UFMG. Belo Horizonte, 2002.

GRADIM, Anabela. O Jornalista Multimídia do Século XXI. In: FIDALGO, Antonio; SERRA, Paulo. (org). Jornalismo Online: Informação e Comunicação Online. Volume I. Universidade da Beira Interior. Covilhã , Portugal , 2003. 
ALÁCIOS, Marcos. Jornalismo Online, Informação e Memória: Apontamentos para Debate. In: FIDALGO, Antonio; SERRA, Paulo. (org). Jornalismo Online: Informação e Comunicação Online. Volume I. Universidade da Beira Interior. Covilhã , Portugal , 2003.

RUBIN, Jeffrey; CHISNELL, Dana. Handbook of Usability Testing: How to Plan, Design and Condusct Efective Tests. Whiley Publishing, Inc, 2008.

\section{Nota}

Esta pesquisa foi realizada no âmbito da disciplina de Teste Formal de Usabilidade do curso de Pós-graduação em Ergodesign de Interfaces, Usabilidade e Arquitetura de Informação da PUC-Rio (2014). Os autores agradecem à participação dos colegas Leonardo Favre e Mariana Costa. 
Recebido em: 30/04/2014

Aceito em: 01/06/2014

\section{Como citar}

SANTÁGUDA, Alberto; MENEZES, Lisle; AGNER, Luiz. Jornalismo online e design de interfaces: avaliação comparativa da usabilidade dos sites G1, Folha de São Paulo e Estadão. Arcos Design. Rio de Janeiro: PPD ESDI - UERJ. Volume 8 Número 1 Junho 2014. pp. 114-131. Disponível em: [http://www.epublicacoes.uerj.br/index.php/arcosdesign]

\section{DOI}

http://dx.doi.org/10.12957/arcosdesign.2014.13929

\section{(c) (1) (2)}

A Revista Arcos Design está licenciada sob uma licença Creative Commons Atribuição - Não Comercial - Compartilha Igual 3.0 Não Adaptada. 